Mercator, Fortaleza, v.19 , e19015, 2020. ISSN:1984-2201

\title{
SOCIOSPACIAL FRAGMENTATION
}

https://doi.org/10.4215/rm2020.e19015

\author{
Eliseu Savério Sposito $a^{*}$ - Maria Encarnação Beltrão Sposito b
}

(a) Dr. in Geography. Professor at the Faculty of Science and Technology (UNESP), São Paulo (SP), Brazil.

ORCID: https://orcid.org/0000-0003-2340-9290. LATTES: http://lattes.cnpq.br/8520043515434606.

(b) Dra. In Geography. Professor at the Faculty of Science and Technology (UNESP), São Paulo (SP), Brazil.

ORCID: https://orcid.org/0000-0002-0421-7253. LATTES: http://lattes.cnpq.br/4150193798058154.

\author{
Article history: \\ Received 13 April, 2020 \\ Accepted 20 April, 2020 \\ Publisher 15 June, 2020
}

(*) CORRESPONDING AUTHOR

Address: Rua José Levy Guedes, 606. CEP 19060-260, Presidente Prudente, São Paulo, Brasil.

E-mail: essposito@gmail.com

\begin{abstract}
The concept of socio-spatial fragmentation can be seen, as analyzed in this article, through different conceptions, be it considering as a polysemous or multifunctional concept. Our attempt, to go beyond that, is to rehearse a conceptual proposal more precisely, starting from authors who have already worked on the subject/topic, in urban cutting concerning the periphery of capitalism. Bearing in mind the innumerable possibilities for dialogue, from several authors' ideas in different areas of knowledge - Geography, Sociology and Architecture - we have outlined dialogue with a number of schools from the start ultimately to arrive to an interpretation of the concept, adopting the expression socio-spatial fragmentation.
\end{abstract}

Keywords: Socio-Spatial Fragmentation, Contemporary Urbanization.

\section{Resumo / Resumen}

\section{FRAGMENTAÇÃO SOCIOESPACIAL}

O conceito de fragmentação pode ser visto, como analisamos neste artigo, por meio diferentes concepções, seja considerando-o como conceito polissêmico ou multifuncional. A nossa proposta, para ir além disso, é ensaiar base conceitual com maior precisão, partindo de autores que já trabalharam o tema, em recorte urbano no que consideramos a periferia do capitalismo. Levando em consideração as inúmeras possibilidades de diálogo, a partir das ideias de vários autores em diversas áreas do conhecimento (Geografia, Sociologia e Arquitetura), delineamos o diálogo com diferentes escolas desde o ponto de partida para chegarmos, no final, a uma interpretação do conceito, adotando a expressão fragmentação socioespacial.

Palavras-chave: Fragmentação Socioespacial, Urbanização Contemporânea.

\section{FRAGMENTATION SOCIO-SPATIALE}

Le concept de fragmentation socio-spatiale peut être examiné, comme nous l'analysons dans cet article, à travers différentes approches, c'est-à-dire comme un concept polysémique ou multifonctionnel. Pour dépasser ces points de vue. Notre tentative est de évaluer une proposition conceptuelle avec plus de précision à partir d'auteurs qui ont déjà travaillé sur le thème, dans un contexte urbain que nous considérons comme la périphérie du capitalisme. Compte tenu des innombrables possibilités de débat/dialogue/d'échange, basées sur les idées de plusieurs auteurs issus de diversdomaines de la connaissance (géographie, sociologie et architecture), nous esquissons le dialogue avec différentes écoles au départ, pour arriver, au final, à une interprétation du concept, en adptant l'expression fragmentation socio-spatiale.

Palabras-clave: Fragmentation Sociospatiale, Urbanisation Contemporaine. 


\section{INTRODUCTION}

This article arises from the authors' experience in developing a research project focused on understanding Brazilian urbanization, based on the concept of fragmentation, which we call socio-spatial. As the central object, the word fragmentation appears throughout the text, but not always with the term we have adopted. It appears tout court or accompanied by other qualitative adjectives chosen by the cited authors.

Initially, our theme is developed through some explanations of why we have selected this concept, which does not have a single meaning. Instead, over time, different concepts are adopted, which can be identified as the ideas of several authors and other areas of knowledge.

To begin with, we have established two perspectives to organize the ideas of those writers who have contributed to the development of this concept. The first refers to the polysemy that characterizes fragmentation and, to address this profile, we have drawn on the works of Guzmán and Hernández (2013), Rhein and Elissalde (2004), Santos (1990), Lefebvre (1989), Rémy (2002), and Navez-Buchanine (2002). This interaction is ongoing, even when dealing with other approaches.

The second perspective concerns the multidimensionality of the concept of fragmentation, beginning with Sposito and Góes' (2013) book that was published within the scope of the working group to which we belong and that studies socio-spatial fragmentation in medium-sized cities. We go on to examine the contributions of Navez-Bouchanine (2002) and Rémy (2002).

Having presented our ideas about the polysemy and the multidimensionality of the concept, we aim to establish a greater conceptual precision for the idea of fragmentation and, to this end, we draw on the works of Paquot (2002), Séguin (2011), Gervais-Lambony (2001), Prévot-Schapira ( 2008), and Salgueiro (2001).

In our focus on the concept in the periphery of capitalism, we opted for countries of the "South", as is explicit in the work of Navez-Bouchanine (2002) and includes Edward Soja, David Harvey, Saskia Sassen, and Peter Marcuse. In this section, we interact with Prevôt-Schapira and Pineda (2000), Haeringer (1991), Dardot and Laval (2016), Catalão and Magrini (2016), and Harvey (2016), then return to Lefebvre (2001) .

As there are countless possibilities to focus on, from authors in widely different areas of knowledge, we outline our arguments based on Geography, Sociology, Architecture, and Philosophy to finally present some analytical cuts and methodological perspectives that we highlight so that the understanding of the concept occurs through its material and symbolic elements.

The route taken to develop the concept and arrive at the analytical cuts and methodological paths stems from the reflections presented in our current research project, entitled "Socio-spatial fragmentation and Brazilian urbanization: scales, vectors, rhythms, forms and content", which has impelled us to face the concept's complexity because it "encompasses numerous forms of socio-spatial differentiation ... especially those that result from the multiple inequalities that mark the urban experiences of city dwellers in Brazil" (Sposito, 2018, p. 5-6).

\section{THE CONCEPT OF FRAGMENTATION: DIFFERENT CONCEPTS}

Whether related to economic, social, cultural, or political dimensions, historically the analysis of spatial differentiation has been important for those professionals focused on the study of urbanization and cities. Convergences and divergences, consensuses and conflicts, coalitions, and contradictions of different orders have been made clear, either through the study of socio-spatial segregation and self-segregation or through a comprehension of the forms and manifestations of socio-spatial inclusion and exclusion. These dynamics should be associated with the socio-spatial fragmentation process but are often presented superficially as synonyms for it. Our understanding is that such processes (segregation, self-segregation, exclusion, and differentiation, defined as urban, spatial, socio-spatial, etc.) compose socio-spatial fragmentation, in multiple combinations that depend on the urban realities taken as references. 
Therefore, we reject the view that these are similar processes that can be adopted as synonyms. Our starting point is that they are distinguished by nuances and, more notably, as a more recent concept socio-spatial fragmentation can encompass the others, without surpassing or discarding them, but instead incorporating them into the reflection.

We invite the reader to reflect with us, seeking greater conceptual precision by embracing the idea of socio-spatial fragmentation.

\section{A POLYSEMIC CONCEPT}

We have already indicated in more than one publication (SPOSITO, 2011; SPOSITO and GÓES, 2013; SPOSITO, 2018) that the term "fragmentation" is polysemic and that many contents have been attributed to it, as it has been adopted to deal with contemporary processes of different shades. Often, this conceptual tool is used both to analyze general dynamics on a world scale, substantiated by contemporary globalization, and to explain changes in the forms of spatial structuring of cities, in a multitude of spatial possibilities and situations. Thus, it is a multi-scale concept, but scholars must make clear which analytical plans they favor, and the geographical scales selected for their research.

In their search for a definition, Guzmán and Hernández (2013), whose focus is on architecture, also highlight the polysemic nature of the word fragmentation. Despite this assumption, the authors associate the term with metropolization, limiting the possibilities of understanding the concrete bases of fragmentation and the concept itself (SPOSITO, 2004), since they restrict the geographic scale of its application.

For them, based on form, fragmentation can, as a territorial process, be formed by three subprocesses: social fragmentation, physical fragmentation, and symbolic fragmentation, which is similar to the position of Prévôt-Schapira (2001), which will be analyzed below. However, at the same time, it is distinguished by the perspective adopted by the two authors.

For Guzmán and Hernández (2013), in the modern city of the mid-twentieth century, fragmentation serves as a parameter of comparison between "urban pathologies" and the "ideal of the city". In the postmodern city, it serves as a basis for "comparing social, economic, cultural and ethnic inequalities, which consequently are reflected in space and, specifically, in cities". After this, social, economic, or cultural differences indicate the transformations inferred by the use of the broadening concept, including "... to interpret the social behavior of citizens and their perception of urban space" (p. 44).

Thus, by adopting the idea of "urban pathology" and stressing the role of individuals over groups and institutions. a certain correlation is established between the city and living organisms. Emphasis is given to form over content, leading to the urban models of the networked city, the extension of private neighborhoods, the new centralities, and urban archipelagos.

Although this is Guzmán and Hernández's (2013) main focus, they also point to the social aspects of fragmentation and segregation, which are: social differentiation, social identification, and territorial identification.

Rhein and Elissalde (2004) affirm that "in urban analysis, to insist only on the aspect of fragmentation hides the dimension of the exchanges, encounters, and social mixture that is the basis of all social life" (p. 125). It is necessary to "consider the different attitudes of the actors engaged in diagnosing the state of urban society and the relationships between these attitudes, the engagements on which they are founded, and the readings that these actors propose" (p. 125). From this perspective, it is evident that, for these authors, fragmentation is also more form than content, that is, it is understood within the plan of the urban fabric. This is why they warn that it is necessary to go beyond this concept to contemplate the actors engaged.

Navez-Bouchanine (2002), who carried out an important bibliographic synthesis on the theme, argues that fragmentation is also related to urban form on the city scale, which is the result of "an 'internal' work, within a defined unit: zoning, specialization, the end of 'mixed' fabrics, the main elements are focused on the critique of the city in pieces or mosaic, from the perspective of a narrow and totalizing functionalism (p. 56). The "physical separations induced by planning, notably those concerning circulation and breaks in the landscape, are equally designated as generators of 
fragmentation of the traditional city" (p. 57). However, given her view supported by several authors, she seeks to overcome the emphasis on forms.

Indeed, this view can be considered relatively narrow, since much of the literature does not deal with fragmentation merely at the level of the urban form, on the contrary, it is considered essential to reveal various analytical plans that are designed to understand this complex process.

Polysemy can also be viewed as the "... notion of micro-fragmentation [that] is one of the most recent forms expressed by this trend and designates (...) the juxtaposition of very limited and circumscribed, socially specialized spaces whose social rupture indicates the absence of exchanges and social relations" (NAVEZ-BOUCHANINE, 2002, p. 57). The concept is also identified by less frequent fractal reading, lacking global geometry, as the city appears with irregular, fragmented morphology with no global organization. In this case, development is not seen as a hierarchical structuring process, but only as "replication" (p. 60).

Lefebvre (1989) also uses the polysemic sense of the concept of fragmentation which has become the basis of many of his epistemological studies. This author starts from a wide criticism of modernity, dealing with the "social crises engendered by the evolution of capitalism". In this context, the concept of fragmentation has "close and more or less synonymous meanings" according to the use of the idea of the " exploded city", that gains the status of "a type of shortening of the problematic and negative evolution of the urban and society" (p. 41). Lefebvre goes on to show that, for these reasons, there is no "specificity or originality of the term fragmentation" since "it adapts perfectly in the dominant analysis when it does not guide it" (p. 41). Although dealing with the "exploded city", a metaphor that alludes more to form, the author refers to the urban and not just the city. In associating fragmentation with the crises of capitalism, Lefebvre indicates that the concept of fragmentation contemplates both form and content. His outline of the concept of fragmentation differentiates him from the other authors mentioned.

On naming one of his books Metrópole Corporativa Fragmentada, Santos (1990), introduces this idea to Brazilian Geography. In the section entitled "Relative immobility and fragmentation of the metropolis", he addresses the transport difficulties of residents in the periphery and focuses on the tendency to territorial extension associated with the increase "... of relative price differentials not just between the center and the periphery" (p. 90). However, he does not quite develop the concept of fragmentation, although, in our opinion, he presents many elements to reflect on this notion. Furthermore, in the Introduction, he highlights the importance of Political Economy for Urban Geography, stressing that "... the city itself, as materiality, has to be placed in the foreground, because it imposes itself on the rest as a framework". In other words, the city "is a dynamic data" that is fundamental to understanding "social life itself" (p. 11).

Polysemy that adopts the idea of fragmentation does not end at this point in our dialogue. It could be expanded with other arguments, but here we will deepen our discussion by addressing the concept's multidimensionality.

\section{A MULTIDIMENSIONAL CONCEPT}

Part of the concept's breadth and polysemy is associated with the fact that it refers to multiple dimensions since it can be approached from various natures of differences and forms of separation in space. Hence several adjectives are associated with it.

Navez-Bouchanine (2002) is the scholar who best shows this multidimensionality. Based on socioeconomic differences, fragmentation means a "Strong new overlap of the economic and social, acting on various forms of proximity and co-presence in space" (NAVEZ-BOUCHANINE, 2002, p. 65). The limits to this fragmentation are a) physical and temporal inertia (p. 66); b) socio-demographic characteristics; c) the specific effects of the territories themselves on social reproduction considered as generators of fragmentation (p. 68, emphasis added by the author).

For Navez-Bouchanine, the fragmentation associated with economic changes is generally perceived as negative, such as new forms of regulation and income formation and the role of work systems, which value the differentiation in the urban space of the effects of residential location according to the land prices and, on the other hand, employment conditions (formal or informal, their 
incidence in the city, popular housing developments, etc.).

Working in a similar direction and adding other points, Sposito and Góes (2013) consider that, in the period of globalization, the "homogenization of spaces and people is combined with the efforts of differentiation" for agents who build "material barriers" and adopt "strategies separation and control in relation to others", raising the need to maintain "security and status". This has an impact on the urban phenomenon of the "growth of medium-sized cities" with the increase of their territorial extension, as opposed to the "weakening of relations between city dwellers" (p. 294-295). This movement results from the intensification of the self-segregation process, indicating that this is one of the dimensions of socio-spatial fragmentation in urban spaces, although not the only one. From this point of view, multidimensionality is attributed to the concept, alongside its multiscalar nature.

The fragmentation of the cultural base is a threat to the right to difference, whose absence constitutes a limit to urban life. It also takes place under the cultural dimension, in the way it is comprehended, that is, how the perception of fragmentation behaviors and practices occurs. These are approaches of a more ethnographic or anthropological character, both very important in urban studies and the understanding of fragmentation (NAVEZ-BOUCHANINE, 2002).

For the same author, social fragmentation is seen from the social transformations of advanced modernity or postmodernity, or even as consequences of post-Fordism. One of the features of postmodernity is its fragmented nature, characteristic of the end of great narratives. Marketing allows different groups to create their particular codes. The relationship between the social and spatial alter profoundly: relocation/deterritorialization with reciprocity in relocation/reterritorialization. The new connections are fluid, plural, and extend in time and space.

Similarly, to the discussion on polysemy in the previous section, the term multidimensionality also entails a certain ambiguity or epistemological duplication. Rémy (2002) points out that fragmentation can be descriptive or interpretive. The former “... may contain information about populations' spatial distribution, [...] thus, a group may be fragmented because it is distributed among different spaces". Interpretative fragmentation is the description of a spatial dispersion that implies that a group is diluted and loses its coherence" (p. 106). Moreover, he considers that "cohesion results not from physical contiguity, but from exchanges and encounters in barely visible interstices" (p. 107), indicating little confidence in the need to establish a new concept, perhaps because there is no clear fragmentation, despite the loss of some physical contiguity that marked the city of the past.

In this sense, Rémy (2002) continually challenges the concept by emphasizing that, in methodological terms, "the essential thing is to find a good record of distance-proximity and the activities around which exchanges can connect" (Rémy, 2002, p. 107). This author, with his contributions to Sociology, also states that "inhabiting is plural: the same person can feel, in his city, in several places. The density of interactions does not rest on the continuity of the physical space" because "the city is no longer necessarily a compact space" (p. 108). Displacements, another aspect to be considered in methodological terms, are carried out at different rates, and may contain different representations of different places, allowing the connection of different places, such as discontinuous centers.

For Rémy (2002), "likewise, the multiplication of technical objects creates increasingly broad chains of interdependence" and at different spatial scales (p. 110), in addition to actors with different intensities of performance. He says that the term "fragmentation seems to be loaded with assumptions that limit the freedom to analyze and interpret new phenomena" (p.105). Quoting B. Poche (1985), he recalls that "fragmentation is not the consequence of disaggregation, but a basic property of social life" because "the collective dynamic rests on the constitution of particular universes that are the places where inter-comprehension take place" (p. 105). Political mediation emerges along this path, and the State is important for civil society; it is not reduced to it, but relies on it. Perhaps Rémy's (2002) discomfort regarding the use of the concept is associated with the fact that the European reality is the reference for his reflections, where fragmentation, which we consider socio-spatial, is less intense than that observed in other territories, as will be seen below.

While socio-spatial fragmentation is based on the unequal access of different social segments to services and urban spaces, as well as the protagonist relationships and the distribution of power in the direction of cities, in a context in which the defense of private property and exchange value is 
fundamental to the reproduction of capitalism itself (HARVEY, 2014), the search for the right to the city starts from the understanding that the collective and integrated dimension of urban life must be recovered, not in the sense of returning to the traditional city, but related to a renewed and transformed urban life (LEFEBVRE, 2001).

Regardless of the intensity with which it occurs in cities of different socio-spatial forms, based on the above, we can conclude that the plurality of meanings of the concept, its multidimensionality, and its multiscalar nature simultaneously indicate its complexity. However, it must be adopted with criteria and accuracy, so that "polysemy" is not the basis of its own weakening. In order to contribute to the idea of fragmentation reaching the status of concept, it is essential to advance the discussion.

\section{FOR GREATER CONCEPTUAL PRECISION OF THE EXPRESSION SOCIO-SPATIAL FRAGMENTATION}

In the foundation of our research, socio-spatial fragmentation is understood as a process and not a fact or a consequence. This is our starting point on the conceptual plane, that is, a recognition of its essence, which leads to a set of questions:

-What are the components of the socio-spatial fragmentation process?

-What is the origin of the concept and how is it constructed?

-How is it distinguished from previous forms of socio-spatial differentiation in urban spaces?

-How is it articulated and distinguished from the concept of segregation?

Paquot (2002) started the debate on fragmentation from the definition of "a fragment". He argues that this word designates the part of a whole that can be split up. So, adopting the idea of fragmentation presupposes the interpretation that space can or could form a homogeneous whole.

However, the contemporary city is far more fragmented than the city in past times (ancient, medieval, modern). Going back to Antiquity, Paquot (2002) traces a philosophical interpretation of the term, referring to Heraclitus' definition of fragments. For this philosopher, fragments form a unit that has a different nature from the original parts. When forming a system, they appear differently than when they are seen separately, a condition in which they are obscure. However, when considered together, they form a harmonious whole. Each fragment becomes indispensable because it gives meaning to the whole.

This introduces an important aspect for science: human beings' capacity for abstraction. On the plane of thought, humans can comprehend the meaning of a fragment as part of the whole. It can be perceived as the possibility of the manifestation of the person's thought, which can be questioned as an element of the world and being. It is an element in a constant process of construction, in a movement of becoming, and cannot be represented as dogma. The fragment manifests itself as a gignomenon, that is, things that come to pass. Paquot understands the city in the same way: as a whole that always evolves and, therefore, is never finished. He views the European city as the city of modernity that does not seek unity, instead it forms a totality in constant change, which is built and destroyed according to the speed of technological innovations and the cycles of the capitalist economy.

Paquot (2002) uses cloth as a metaphor to replace the idea of the urban fabric. He states that a cloth can be folded, stained, and crumpled and is more reminiscent of topography than the image of fabric. The cloth is the result of the warp and weft, it is not uniform or flat and it has details in its finish. The fragment, part of the cloth, is not a principle, but a result, thereby remembering the juxtaposition of hybrid territories. Furthermore, the danger represented by the fragmented city is the exclusivity of some groups in relation to others, transforming the city into differentiated, discriminating private areas. Paquot's view of fragmentation as a result is not completely similar to ours because, when taken as a process, we consider fragmentation as both a result and a condition.

In the book organized by Navez-Bouchanine (2002), cited above, based on various authors, the editor's own text offers a broad view of the different perspectives, demonstrating how the concept of fragmentation is treated. Although always related to segregation it is distinguishable from it.

We found the first section, entitled "fragmentation, a state of the art", of particular interest. 
Initially, the author deals with the concept's emergence, signaling some historical milestones. In the late 1980 s, the use of the term was widespread, but it had already been used in the 1960s, in a more restricted sense, to designate "the horizontal and vertical fractioning of the city in the suburbanization phase" (p. 19). In the 1990s, there was an avalanche of studies on the subject, which largely explains the polysemy mentioned in the earlier part of this text.

Socio-economic, anthropological, and philosophical contributions aiming to "designate a more global phenomenon, with greater scope", resembling the "fragmentation of urban society" suggest "a unitary, organic, solidary city" "succeeded by a random set of "exploded' socio-spatial forms, marked by strong territorialization processes, not only cut from each other but cut out by a type of social and political reduction" (NAVEZ-BOUCHANINE, 2002, p. 19).

Séguin (2011) concurs and adds a new element, highlighting the tendency for parts of the city to reveal a certain autonomy, where there is coexistence between various sectors in the same city, like "... a mosaic of uncoordinated overlapping fragments" (SÉGUIN, 2011, p. 69). In other words, it is possible to empirically identify ruptures between different parts of the city when it is observed from the perspective of different planes (economic, social, and political), as affirmed by GERVAIS-LAMBONY (2001), or different references (social classes, places of residence, etc.).

Citing Lefebvre (1989), Navez-Bouchanine (2002) recalls that the concept of fragmentation has the "planetarization of the urban" as its backdrop, which "generates a strong homogenization" that, in turn, "goes hand in hand with the fragmentation of social space between spaces for leisure, work, residence and reinforcement of socio-spatial differentiation"(LEFEBVRE, 1989, p. 40, author's emphasis).

For this author, since the studies at the Chicago school, fragmentation makes sense, when the scientific debate "begins to take account of the limits to the supposed virtues of proximity and the social 'mixture' of complex, sometimes contradictory, effects of injunctions for 'de-segregation"' (p. 63), when violence manifests itself revindication.

Taking the finding that there are "accentuated socio-spatial polarizations" (PRÉVÔT-SCHAPIRA, 2008) as a reference, Navez-Bouchanine (2002) analyzes them in a space-time perspective not merely as a given but recognizing them as a profound transformation that affects contemporary urbanization.

One of the basic facts of these polarizations is that individuals or groups who have a certain identity tend to group in common spaces marked by elements that designate or congregate their identity. Many of these spaces are appropriated exclusively (NAVEZ-BOUCHANINE, 2002), as evidenced by the growth of gated residential spaces that are controlled by security systems (SPOSITO and GÓES, 2013), revealing spatial distance and separation From the perspective of understanding urban life, they indicate a huge departure from the idea of the city as a global space of integration (NAVEZ-BOUCHANINE, 2002).

After carrying out a historical inventory of the concepts of segregation and fragmentation, Navez-Bouchanine (2002) demonstrates some more conceptions of fragmentation and warns that "(...) on the one hand, fragmentation is not the only word to be used with the different meanings to which it refers" and, on the other hand, "the history of the emergence of the notion indicates a strength capable of transcending all contradictions" (p. 45). Influenced by urban planning policies, the concept of fragmentation became the object of studies that attempt to distinguish which processes can contribute to it. With regard to the city, "urban fragmentation is characterized by a direct emphasis on the question of the unity and division of city space" (p. 47, author's emphasis). Then again, the fragmentation by the city's shape due to its expansion and spread is also the source of the concept, which also addresses socio-spatial fragmentation, developed from ghettos, closed communities, and territorial enclaves.

Giving important elements to grasp the substance of this process, the scholar Prévôt-Schapira (2001) presents fragmentation synthetically and clearly, associating it with different types of components. These are spatial when referring to "physical disconnection [and] morphological discontinuities". The social dimensions refer to the "community withdrawal [and] exclusive logics", whereas the political dimensions are supported by the "dispersion of actors and the autonomy of urban management and regulatory devices" (p. 34).

In themselves, these components and dimensions only gain spatial-temporal contextualization if 
the analysis is linked to a broader process associated with the transition from the Fordist economy to the flexible economy, which not only has consequences for the city but is supported by new logics that guide the production of urban space. This is the understanding of Salgueiro (2001), who recognizes the "fragmented city under construction" through:

1) the loss of the center's hegemony with the "multiplication of new centralities";

2) the importance of real estate producers, with the creation of "mixed areas", destined to commerce, services, and housing;

3) the appearance of "socially dissonant enclaves within a fabric with a certain morphosocial homogeneity", with "contiguity without continuity";

4) an increase in the "complex flows crossing the territory", dissociating the areas they pass through (material and immaterial flows) from other areas (p. 116).

Finally, to clarify our point of view, at this point it is important to justify why we use the adjective socio-spatial with the noun fragmentation since, as we have observed, other descriptors are adopted, including urban, cultural, socio-political, and political. We believe that fragmentation "always has a double determination and expression: spatial and social" (SPOSITO and GOES, 2013, p. 303), both from the material point of view and in its symbolic dimension, revealing the practices constituted by the new forms of separation in the city. This perspective is reinforced by the fact that the dispersed city (on any scale considered, be it the metropolis or the medium-sized city), is a condition of "new contents and practices" (SPOSITO, 2011, p. 140). Thus, in addition to the duo of determination and expression, fragmentation is constituted of dialectically articulated movements, which reinforces the idea of the process.

\section{SOCIO-SPATIAL FRAGMENTATION ON THE PERIPHERY OF CAPITALISM}

We recognize fragmentation as a general process, typical of contemporary urbanization, and we understand that the concept does not only apply to past periods of urban life. It is important to recognize the particularities of this process in countries on the periphery of capitalism, where different hues and shapes of cleavages marked by differentiation and inequality give it many shades.

Navez-Bouchaine (2002, p. 20) qualified the cities that we define as the periphery of capitalism, such as the cities of the South, taking the North - South divide as a reference; the inheritance of the different conceptions of development that spread from the 1950s onward. Thus, it is related to the development - underdevelopment pair. The author points out that the notion of fragmentation appeared with almost simultaneous uses, both converging and diverging in countries on the periphery of capitalism.

Navez-Bouchaine begins her analysis of fragmentation in the South examining "dual" cities, focusing on the Maghreb, where there are cities "of two worlds" (colonial and indigenous, or formal and informal city), implying that she already recognizes an origin from the city, the embryo of a certain socio-spatial fragmentation. For her, the dual reading of the cities of the South led to the formation of the "idea of a cut, an opposition between two very different parts populated by different populations" both "from an ethnic point of view" and "from a socio-economic, cultural point of view, ... that dispensed with unity" (NAVEZ-BOUCHANINE, 2002, p. 22, author's emphasis).

This idea of the dual city is present in the theoretical construction of numerous outstanding authors, many of whom have carried out critical readings of the city, such as Santos, Soja, Harvey, Paquot, and Rémy. To justify the social fragmentation of southern cities, Navez-Bouchaine argues that these authors have reinforced the idea that "dualism has long imposed itself as a grid of social and spatial reading" (p. 22).

Thus, the cities of the Southern hemisphere form mosaics or puzzles, with evident separation of the infrastructures (their quality and nature). The role of distance, separation, and disarticulation between them prevails, and there is a large-scale incidence of informal businesses (NAVEZBOUCHANINE, 2002, pp. 59-60).

However, when dealing with the South, the same author does not disarticulate it from global 
processes, but instead reiterates the criticisms directed at the authors mentioned in her work. This restatement is proven by the fact that "the progressive passage of a spatial analysis of the southern city from the paradigm of colonial or post-colonial dualism" through the reading of the "space cut" produces "two very different partial readings of the city" concerning "spatial and socio-spatial fragmentation, increasingly associated with globalization". The notion of globalization, for the author, raises questions "about transformations on a broader scale" (NAVEZ-BOUCHANINE, 2002, p. 27).

Precisely for this reason, in the literature from the North, such as the Anglo-Saxon, in the 1980s, there is a "pathological" division of the city at the same time that the dual cut designates facts about the cities of the Northern hemisphere (p. 28). Here, Soy, Harvey, Sassen, and Marcuse are cited, for example, even stating that "... the dominant explanation aims at the transformations that affect production, notably industrial production in the post-Ford era, as the particular dynamics of spatialization that characterize socioeconomic evolution" (NAVEZ-BOUCHANINE, 2002, p. 28).

Jumping from dualism to fragmentation reinforces the idea that the adoption of the concept in the North was supported by analyzes previously made for the South. Navez-Bouchanine (2002) considers that, from the case of New York, "a perspective of going beyond is open: in fact, the global city is, at the same time, dual and fragmented; dual by the opposition between nodal segments, the space connected to the global economy and, the rest, namely the space of communities without power" (p. 31)

In the case of France, in the 1960s and 1970s, fragmentation/secession were not an important object of research but became the target of studies because of research carried out in southern (mainly African) cities. Therefore, dualism and fragmentation have "been outside of the national debate for a long time, when the issue of the city's socio-spatial differentiations has been important and ancient for both geographers and sociologists" (NAVEZ-BOUCHANINE, 2002, p. 35).

In France, the social fracture and the spatialization of the social issue were studied in the 1990s and there was a rise in interest in social exclusion. However, the "... term fragmentation ended up spreading widely in French urban research with meanings similar to international developments"(NAVEZ-BOUCHANINE, 2002, p. 39).

Within the scope of the extensive space that the above author named the South, we have extracted the analysis dealing with Latin American urbanization to get even closer to the object of our research medium-sized Brazilian cities. We consider the way Prévôt-Schapira and Pineda (2008) characterized the socio-spatial fragmentation in this paragraph very didactic. They found that considering the general spatial, social and political elements highlighted in the previous paragraph, socio-spatial fragmentation in the Latin American subcontinent evidences a new level of particularization in the process, which is generally

1) the role of public policies and "the new modes of governance of continental metropolises";

2) through "transformations associated with globalization and the new strategies of business management";

3 ) though the "often contradictory relationship between social change and changes in the urban structure" (PRÉVÔT-SCHAPIRA and PINEDA, 2008, p. 75).

As we have already emphasized, we favor the third direction, but it cannot be examined alone. Instead, it is always necessary to bear in mind the inseparability of the three aspects.

These dynamics were identified in medium-sized cities studied in previous works: 1) "the redefinition of the roles of the central area" and, from there, "of urban and interurban centrality" (as a process of urban restructuring); 2) "the growth in the number of enclaves", gated residential spaces associated with the idea of security; 3) contiguity without continuity associated with territorial expansion and the peripheral location of new real estate projects for housing, commerce, and services (SPOSITO and GÓES, 2013, p. 298).

However, the fragmented city has been studied for longer in Brazil and here we have already drawn attention to Santos' book (1990). Navez-Bouchanine (2002) refers to authors like Ribeiro and Santos Filho, for example, as producers of studies about Brazil. Some research is more specific, Navez-Bouchanine conceptualizes micro-fragmentation (Caldeira, 2000) and security fragmentation (Haeringer, 1991), demonstrating that the refinement of studies on fragmentation in Brazil has also resulted in new scales of approach. 
Since Milton Santos, in Brazil fragmentation has been studied at different geographically conceived scales. The concept was used "both to designate the fragmentation of the national territory and the city and that this similarity of denomination directly feeds two sources of inspiration for geographic analysis". The first is called "neo-Marxist and postmodern" and the second the "spatialization effects of advanced capitalism". Although the shadow of dualism hovers over these statements, they are important to reiterate the characteristics of "southern" cities, because they support "the more general theses of the effects of globalization in developing countries" (in this case, development as a process and not an economic stage). Thus, from dualism to fragmentation "the reading of urban distribution by Brazilian [scholars] (...) appears, therefore, to be linked to the economic question and the internationalization of capital, from colonization to globalization" (NAVEZ-BOUCHANINE, 2002, p. 24 ). Navez-Bouchanine's conclusions are based on a small number of studies, mainly carried out in metropolitan areas almost two decades ago, leading to the conclusion that they do not reflect the broader production of research of the different dimensions of cities in Brazil.

SPOSITO (2018) recalls that "an important aspect for understanding the process of socio-spatial fragmentation concerns the disjunctive principle that commands the production and appropriation of urban spaces within the ambit of neoliberalism, in the terms of Dardot and Laval" (2016). In this case, neoliberalism is understood as "a global normative system that favors the dissemination of capitalist logic in all social relations and all spheres of life" because "neoliberal subjectivity (...) erodes the bases of solidarity, of sharing and collectivity, by supporting itself on aspects such as competition and individuality" (p. 8).

The process of socio-spatial fragmentation "leads to the need to reframe and update the idea of 'the right to the city' as suggested, in terms of "an antithetical relationship" CATALÃO and MAGRINI (2016).

\section{SOCIO-SPATIAL FRAGMENTATION AND RESEARCH}

As a summary, this last section is composed of final reflections, to return to some points and, above all, to relate them to the research we are conducting and that generate our discussion.

The diversity of ideas within the concept of fragmentation due to its polysemy, multidimensionality, and its multiscale application, make it vital to understand it better and achieve greater conceptual precision. Viewed from our position in the periphery of capitalism, and considering fragmentation's socio-spatial nature, research is required to strengthen its empirical basis. Both at the scale of the urban network and the urban space and from the urban and the city, we consider it important, as a conclusion, to remember that the socio-spatial fragmentation understood as a more general process, can be focused when taking a part of the reality of Latin American urban areas as a reference, enabling the study of metropolises and intermediate or small cities. These locations cannot be viewed in isolation since they must be understood in the light of the dynamics of contemporary urbanization. In the Brazilian case, more specifically, considering different socio-spatial formations may explain the particularities of the urban network's multiple strata. The cities' singularities make it possible to observe their particularities in different dimensions and scales and enable the comprehension of the similarities and differences that can expose the concept's dynamics in broad terms (Sposito, 2018, p. 10).

These concerns, permeated by different methodological instruments, may point to the deepening of the concept and, above all, illuminate the diversity of the city on the periphery of capitalism as the basis of the five empirical dimensions chosen in our research (habitation, work, consumption, circulation, and leisure), to enrich the concept of socio-spatial fragmentation.

Consequently, adopting the concept requires the proper selection of analytical cuts through which the research is carried out, as well as developing qualitative and quantitative methodological fronts so that present and future investigations cover different cities, in Brazil or another country.

We have selected four analytical segments through which to view the city and contemporary urbanization: a) center, centrality, and mobility; b) daily and spatial practices; c) public spaces; d) the city's production and consumption.

These cuts are guided by the following objectives: 
1. To analyze the transition from predominantly center-peripheral socio-spatial logic to fragmentary socio-spatial logic.

2. To interpret socio-spatial fragmentation through contemporary forms of differentiation and inequality, based on practices associated with urban daily life.

3. To understand the unfolding of the fragmentary socio-spatial logic on the public-private space pair.

4. To identify and analyze the role of political institutions, hegemonic economic agents, and non-hegemonic social subjects in the production and consumption of housing, under the fragmentary socio-spatial logic. (SPOSITO, 2018, p. 10-11)

Regarding methodological fronts that favor quantifiable data, the elaboration of a database that can generate tables, graphs, and maps points to a consecrated path in Geography, which can be conducted using analytical-dialectic analysis. Likewise, both basic and synthesis cartography help to systematize and represent information. From a qualitative point of view, there are methodological approaches such as focus groups, netnography, social network analysis, routes and their representations, and interviews with city dwellers and well-informed agents (Sposito, 2018).

Therefore, our conception of fragmentation, as we hope to have shown in this text, is based on the understanding that this process has objective and subjective, material and symbolic elements. All different dimensions, that in addition to measurement, require, above all, sensitivity and observation in the analysis process, through which the essential is selected to understand a given process.

\section{NOTE}

1 - Both in this introduction and throughout the text, the authors are not presented in the chronological order of their publications but are discussed in terms of the nature of their contributions to the debate.

\section{ACKNOWLEDGMENT}

This text is associated with the development of research funded by FAPESP (São Paulo State Research Foundation), in the thematic project modality (process 2018 / 07701-8), entitled “ Socio-spatial fragmentation and Brazilian urbanization: scales, vectors, rhythms, forms and content ". As it is a collective project, its construction is shared with other members of the team based in the Research Group on Spatial Production and Regional Redefinitions (GAsPERR). The text was presented at the XVII EGAL (Encuentro de Geografos de América Latina), held in Quito (Ecuador) in April 2019, on the thematic axis Ciudad y transformaciones urbano rurales.

\section{REFERENCES}

CALDEIRA, Teresa. Cidade de muros: crime, segregação e cidadania em São Paulo. São Paulo: Ed. 34 / Edusp, 2000.

CATALÃO, Igor; MAGRINI, Maria Angélica. Can consumption mediate the right to the (fragmented) city? Brazilian Geographical Journal: Geosciences and Humanities Research Medium, v. 7, n. 1, 2016, p. 19-32.

DARDOT, Pierre; LAVAL, Christian. A nova razão do mundo. São Paulo: Boitempo, 2016.

GERVAIS-LAMBONY, Philippe. La ségrégation dans la grande ville, un essai de définition. In: GERVAIS-LAMBONY, Marie-Anne (Éd.). Les très grandes villes dans le monde. Paris: Atlande, 2001, p. 33-38.

GUZMÁN R., Alejandro ; HERNÁNDEZ S., Kitziah M. La fragmentación urbana y la segregación social. Una aproximación conceptual. Revista Legado de Arquitectura y Diseño. Universidad Autónoma del Estado de México, Toluca, n. 14, 2013, p. 41-55. 
HAERINGER, Philippe. "Mégapoles en images". In: VÁRIOS. Mégapoles et villes géantes, 1991.

LEFEBVRE, Henri. Les illusions de la modernité. Le Monde Diplomatique, maio de 1989.

LEFEBVRE, Henri. O direito à cidade. São Paulo: Centauro, 2001.

NAVEZ-BOUCHANINE, Françoise. "Emergence d'une notion: quelques repères historiques". In: NAVEZ-BOUCHANINE, Françoise. La fragmentation en question: des villes entre fragentation spatiale et fragmentation sociale. Paris: L'Harmattan, 2002, p. 19-103.

PAQUOT, Thierry. "Ville fragmentée ou urbain éparpillé?". In: NAVEZ-BOUCHANINE, Françoise. La fragmentation en question: des villes entre fragentation spatiale et fragmentation sociale. Paris: L'Harmattan, 2002, p.114-118.

POCHE, Bernard. L'espace fragmenté. Paris: L' Harmattan, 1998.

PRÉVÔT-SCHAPIRA, Marie-France. Fragmentación espacial y social: conceptos e realidades. Perfiles Latinoamericanos, n.19, p. 33-56, dez. 2001.

PRÉVÔT-SCHAPIRA, Marie-France; PINEDA, Rodrigo. Buenos Aires: la fragmentación en los intersticios de una sociedad polarizada. Eure, vol. XXXIV, n.103, p. 73-92, dez. 2008.

RÉMY, Jean. "La fragmentation ou metamorfose de la ville". In: NAVEZ-BOUCHANINE, Françoise. La fragmentation en question: des villes entre fragentation spatiale et fragmentation sociale. Paris: L'Harmattan, 2002, p.105-112.

RHEIN, Cathérine; ELISSALDE, Bernard. La fragmentation sociale e urbaine en débats. Information Géographique. V. $68, \quad$ n. 2, 2004, p. 115-126. http://www.persee.fr/doc/ ingeo_0020-0093_2004_num_68_2_2939. Acesso em 14/06/2016.

SALGUEIRO, Teresa. Lisboa, periferia e centralidades. Oeiras: Celta, 2001.

SANTOS, Milton. Metrópole corporativa fragmentada. O caso de São Paulo. São Paulo: Nobel, 1990.

SANTOS, Milton. O espaço dividido: os dois circuitos da economia urbana nos países subdesenvolvidos. São Paulo: Edusp, 2004.

SÉGUIN, Anne-Marie. Les quartiers: des lieux de fragmentation ? Cahiers de géographie du Québec, v. 55, n. 154, p. 69-73, 2011.

SPOSITO, Eliseu S. Geografia e Filosofia. São Paulo : Editora Unesp, 2004.

SPOSITO, Maria Encarnação B.; GÓES, Eda M. Espaços fechados e cidades: insegurança urbana e fragmentação socioespacial. São Paulo: Editora Unesp, 2013.

SPOSITO, Maria Encarnação B. A produção do espaço urbano: escalas, diferenças e desigualdades socioespaciais. In: CARLOS, Ana F. A.; SOUZA, Marcelo L.; SPOSITO, M. Encarnação B. (Org.). A produção do espaço urbano: agentes e processos, escalas e desafios. São Paulo: Contexto, 2011, p. $123-145$.

SPOSITO, Maria Encarnação B. (org.). Fragmentação socioespacial e urbanização brasileira: escalas, vetores, ritmos, formas e conteúdos. Projeto de pesquisa. Presidente Prudente, 2018. 